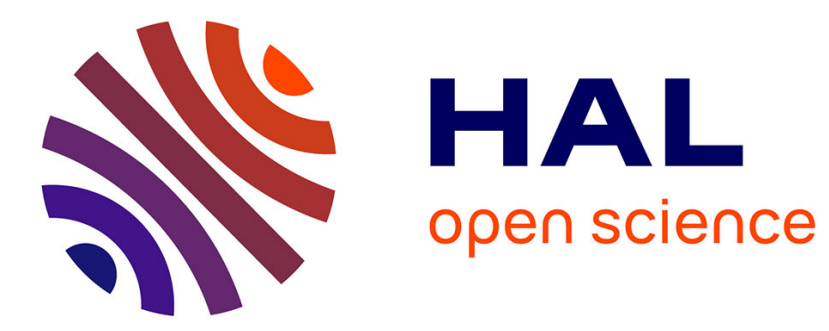

\title{
Dynamic Recrystallization of Ice in Polar Ice Sheets
}

P. Duval, O. Castelnau

\section{To cite this version:}

P. Duval, O. Castelnau. Dynamic Recrystallization of Ice in Polar Ice Sheets. J. Phys. IV, 1995, 05

(C3), pp.C3-197-C3-205. 10.1051/jp4:1995317 . jpa-00253683

\section{HAL Id: jpa-00253683 https://hal.science/jpa-00253683}

Submitted on 1 Jan 1995

HAL is a multi-disciplinary open access archive for the deposit and dissemination of scientific research documents, whether they are published or not. The documents may come from teaching and research institutions in France or abroad, or from public or private research centers.
L'archive ouverte pluridisciplinaire HAL, est destinée au dépôt et à la diffusion de documents scientifiques de niveau recherche, publiés ou non, émanant des établissements d'enseignement et de recherche français ou étrangers, des laboratoires publics ou privés. 


\title{
Dynamic Recrystallization of Ice in Polar Ice Sheets
}

\author{
P. Duval and O. Castelnau \\ Laboratoire de Glaciologie et Géophysique de l'Environnement, CNRS, 54 rue Molière, B.P. 96, \\ 38402 Saint Martin d'Hères, France
}

\begin{abstract}
The deformation and recrystallization mechanisms which control the viscoplasticity of ice from polar ice sheets have been investigated. The high plastic anisotropy of ice crystals is responsible for the development of a non uniform internal stress field within the polycrystal. Strain-shadows produced by sub-grain are observed in polarized light when the rotation recrystallization regime is dominant. Migration recrystallization occurs for a temperature higher than $-10^{\circ} \mathrm{C}$. and is characterized by a unique relationship between recrystallized grain size and stress. The role of dynamic recrystallization in the development of lattice preferred orientations is discussed. Lattice rotation by intracrystalline slip is the dominant mechanism when grain growth or rotation recrystallization occurs.
\end{abstract}

Résumé : Les mécanismes de déformation et de recristallisation contrôlant la viscoplasticité des glaces des calottes polaires sont analysés. La très grande anisotropie du monocristal de glace est responsable du développement d'un champ de contraintes internes dans le polycristal. La recristallisation par rotation se distingue de la recristallisation associée au grossissement des grains par la présence de sous-grains à l'origine d'extinctions onduleuses en lumière polarisée. La recristallisation par migration apparaît pour des températures supérieures à $-10^{\circ} \mathrm{C}$. et est caractérisée par une relation unique entre la taille des grains et la contrainte appliquée. L'influence de la recristallisation dynamique dans le développement de l'orientation préférentielle des cristaux est discutée. Il est montré que la rotation du réseau cristallin par le glissement intracristallin est le mécanisme prépondérant dans les zones où le grossissement des grains ou la recristallisation par rotation intervient.

\section{INTRODUCTION}

Knowledge of the rheological properties of polycrystalline ice is of prime importance for the modelling of the flow of ice sheets. Pimienta and Duval [1] have shown that intracrystalline dislocation glide is the dominant deformation mode. Even at strain rates lower than $10^{-10} \mathrm{~s}^{-1}$, diffusional flow cannot control the deformation [2].

Studies on deep ice cores from polar ice sheets have revealed the development of highly lattice preferred orientations [3-5]. These fabrics, which develop with strain, are the result of the lattice rotation by intracrystalline slip [6;5;7]; they concern the major part of large ice sheets. The observed anisotropy of polar ice is related to this preferred orientation of ice crystals [8-11].

Polar ice is characterized by the occurrence of three recrystallization mechanisms $[12 ; 7]$. Grain growth driven by grain boundary energy is observed in the first hundred meters of the central parts of ice sheets. The grain-structure modification is not associated with the nucleation of grains. This recrystallization regime is achieved by the reduction of the number of grains.Migration recrystallization results from the rapid migration of grain boundaries between newly formed dislocation-free grains and deformed grains [12]. This recrystallization regime giving coarse and interlocking grains is found in warm ice near the bed in Antarctica [3]. Between these two zones, new grains are formed by creep polygonization. Grain boundary migration is 
then driven by both grain boundary and strain energy [12]. As a result, grain size does not significantly change with depth. This recrystallization regime has been termed "rotation recrystallization" by Guillopé and Poirier [13]. The boundary between rotation and migration recrystallization corresponds to a limited range of depths in Antarctica. Clear evidence of this transition was observed by Gow and Williamson [3] in the Byrd ice core. Temperature appears to be the critical parameter for this rapid change of the recrystallization regime [7]. But, the alternance of layers with large and small grains observed in the GRIP ice core in Greenland below $2800 \mathrm{~m}$., with concomitant variations of soluble impurities [14], could be explained by impurity-controlled grain boundary migration.

In this paper, we present an analysis of each of these recrystallization mechanisms. For this purpose, the deformation behavior of polar ice is analyzed using the self-consistent theory developed by Lebensohn and Tome [15]. This model gives information on the state of stress (and strain) within the polycrystal and on the active slip systems of ice crystals. Finally, from considerations on the variation of the stored strain energy with crystal orientation, we attempt to explain the development of lattice preferred orientations in ice from Antarctica and Greenland.

\section{DEFORMATION OF SINGLE CRYSTAL AND POLYCRYSTALLINE ICE}

Figure 1 compares creep data for isotropic polycrystalline ice at $-10^{\circ} \mathrm{C}$. with data for basal glide in single crystals. Basal creep of single crystals shows an inverse transient, consistent with creep which is controlled by the multiplication of dislocations. The stress exponent corresponding to steady-state is about 2 with an activation energy close to $63 \mathrm{~kJ} / \mathrm{mole}$ [16].

When ice crystals are loaded such that there is no resolved shear stress on the basal plane, the creep rates are so small that it is doubtful that they are measured. Only a lower bound for the stress required to produce creep at the imposed rate can be given.

Data given in figure 1 for isotropic polycrystalline ice concern the steady state (or rather the minimum creep rate), which is reached after a strain of about $1 \%[16]$. Taking a power law, the stress exponent $\mathrm{n}$ is close to 3 for axial stresses higher than 0.2 MPa. For conditions prevailing in polar ice sheets (stress lower than $0.1 \mathrm{MPa}$.), the stress exponent is lower than 2. Diffusional creep cannot be responsible for the deformation of polar ice; it yields a viscosity much larger than that deduced from both laboratory and in situ measurements [1]. Intracrystalline dislocation creep is therefore the main deformation mechanism in polycrystalline glacier ice.

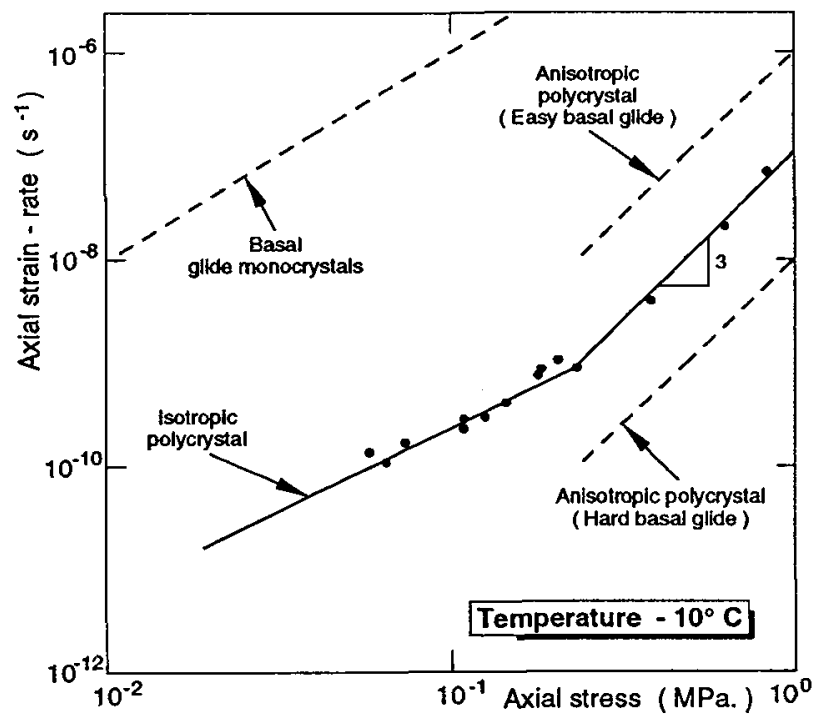

Figure 1. Minimum creep rate as a function of the applied stress for isotropic artificial ice at $-10^{\circ} \mathrm{C}$. Creep curves for basal glide in single crystals and for anisotropic polycrystalline ice are also shown. 
At a given stress, the minimum creep rate of an isotropic polycrystal is at least 3 orders of magnitude lower than that obtained by the basal glide of monocrystals. To understand the relationship between single crystal and polycrystalline ice, slip systems must be examined. As figure 1 shows, a single crystal of ice deforms easily by shear on the basal planes, on the $(0001)<11 \overline{2} 0>$ systems which provide 2 independent systems. Five independent systems are required to reach the uniform strain-rate upper bound. However, caiculations based on the self-consistent method show that extensive plasticity of polycrystals is possible with only four independent systems [17]. For polycrystalline ice, one possibility is that shear occurs also on the prismatic planes on the $(10 \overline{1} 0)<11 \overline{2} 0>$ systems. Under these conditions, deformations are compatible without axial deformation along the c-axis of ice crystals. New results on dislocation mobility have been obtained by $\mathrm{X}$ ray topography using synchrotron radiation. Glide motion of edge dislocations on $(10 \overline{1} 0)$ planes has been observed by Hondoh et al.[18] and Shearwood and Whitworth [19]. But the contribution of these deformation systems to the deformation of polycrystalline ice is low. Another possibility is that shear on the basal plane generates dislocations which then climb on planes normal to the basal plane (giving also two independent systems) [16].

We have used the self-consistent theory developed by Lebensohn and Tome [15] to describe the viscoplasticity of isotropic polycrystalline ice. Since elasticity is not accounted for, this model cannot describe transient creep. Figure 2 shows the variation of the equivalent deviatoric stress with the orientation of ice crystals for isotropic ice loaded in compression. From data given in figure 1, the equivalent deviatoric stress (in relative units) is about 20 . With the self-consistent model, the best agreement is found for the reference shear stress ratio $\tau_{\mathrm{b}=20} \tau_{\mathrm{a}}\left(\tau_{\mathrm{a}}\right.$ and $\tau_{\mathrm{b}}$ are respectively the Reference Resolved Shear Stress for the basal and prismatic systems). Under these conditions, the contribution of basal glide to the deformation of the polycrystal is found to be more than $90 \%$; the remaining $10 \%$ being due to prismatic slip. Moreover, the polycrystal strength deduced from the uniform strain and uniform stress bounds is far from the observed strength of ice. The upper bound predicts an excessive activity of non-basal systems and the lower bound a viscosity one order of magnitude lower than that determined for the isotropic polycrystal.

This high viscoplastic anisotropy is at the origin of a geometric primary creep associated with the redistribution of stress as the softer creep systems relax. This means that, on initial loading, the stress state within polycrystalline ice is almost uniform. As creep relaxes the resolved stress on the basal plane on each grain, load is transferred to the harder systems and an increasingly non-uniform state of internal stress develops .

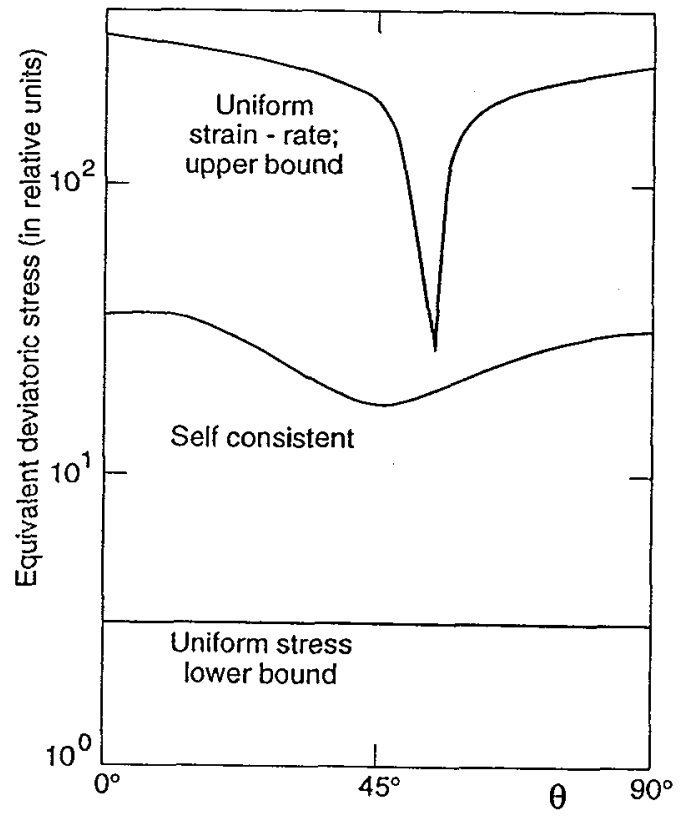

Figure 2. Variation of the equivalent deviatoric stress with the angle between the direction of the applied compressive stress and the normal to basal plane for isotropic ice with $n=3$. 


\section{DYNAMIC RECRYSTALLIZATION OF POLAR ICE}

The grain structure modification in polar ice is achieved via three recrystallization processes which are termed : grain growth, rotation recrystallization and migration recrystallization $[12 ; 7]$. Temperature and strain energy are critical parameters for the occurrence of these recrystallization processes.

\subsection{Grain growth}

At the top of ice sheets, the grain size increases slowly to diminish the grain boundary energy. Grain boundary migration occurs under pressure due to surface curvature. The boundary tends to migrate towards its centre of curvature. The velocity of grain boundary migration $\mathrm{V}$ is such that:

$$
\mathrm{V}=\mathrm{MP}
$$

where $\mathrm{M}$ is the mobility and the driving force $P$ is related to the grain boundary energy $\gamma$ by:

$$
P=\gamma .\left(1 / r_{1}+1 / r_{2}\right)
$$

where $r_{1}$ and $r_{2}$ are the principal radii of curvature of the surface. The variation with time $t$ of grain size is given by :

$$
1^{2}=10^{2}+\mathrm{Kt}
$$

where lo is the surface snow grain size and $\mathrm{K}$ the growth rate (figure 3). Since the crystal growth rate takes the same value in firn and ice [20] the restraint on boundary movement by pores does not appear to be significant.

Grain growth is characterized by a nice equiaxed grain structure (Figure 4). Boundary migration can be slowed down by particles or dissolved impurities [3]. However, impurity concentrations found in Antarctic

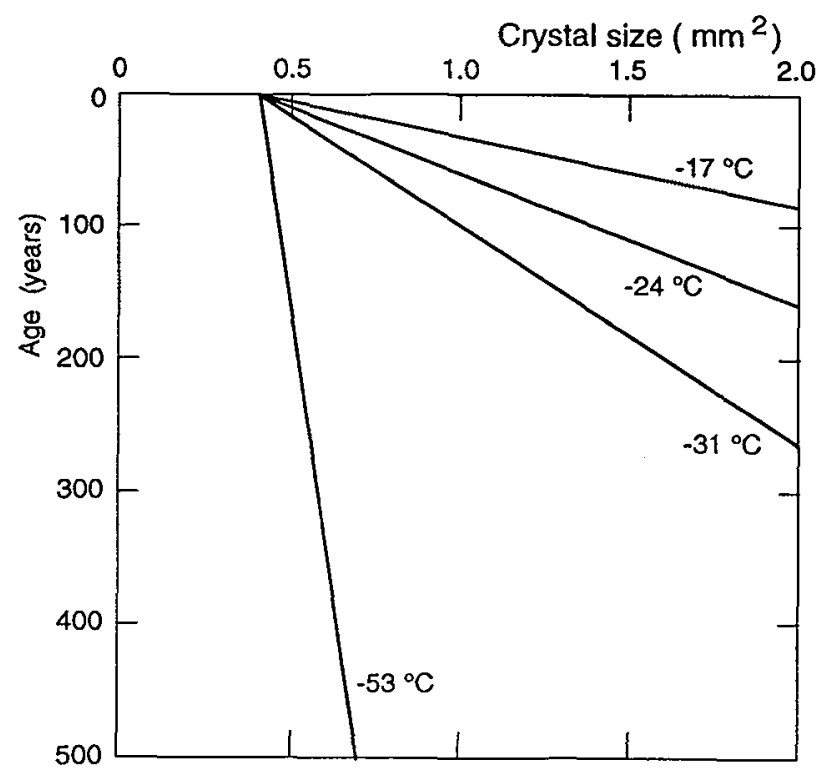

Figure 3. Crystal size - age relationship in polar firn and ice. Maudheim $\left(-17^{\circ} \mathrm{C}\right)$, Southice $\left(-31^{\circ} \mathrm{C}\right)$, Dome $\mathrm{C}\left(-53^{\circ} \mathrm{C}\right)$ (Antarctica), and Site $2\left(-24^{\circ} \mathrm{C}\right)$ (Greenland).

ice are rarely high enough to slow significantly grain growth [20]. Typical concentrations of major soluble impurities in Antarctic ice are 20-100 ppb for $\mathrm{Na}^{+}, \mathrm{Ca}^{++}$, and $\mathrm{Cl}^{-}$[21].

From data on grain growth in polar ice, the boundary velocity is typically $10^{-17} \mathrm{~m}^{2} . \mathrm{s}^{-1}$ at $-50^{\circ} \mathrm{C}$. with a driving force always lower than $50 \mathrm{~J} / \mathrm{m} 3$. For grain growth to occur, strain energy must be lower than that induced by the curvature of boundaries. At Vostok (Antarctica), grain growth is observed down to $2000 \mathrm{~m}$. and the strain rate is about $10^{-13} \mathrm{~s}^{-1}$. With this strain rate, a moving grain boundary can absorb lattice dislocations and makes strain energy low compared with the driving force for grain growth. Grain boundary migration associated with grain growth may therefore be an efficient accommodation process for 
intracrystalline dislocation glide. The small value of the stress exponent observed at low stresses (Figure 1.) could be related to this recovery process which is not driven by strain energy. A sort of Harper-Dorn has been suggested by Lliboutry and Duval [2].

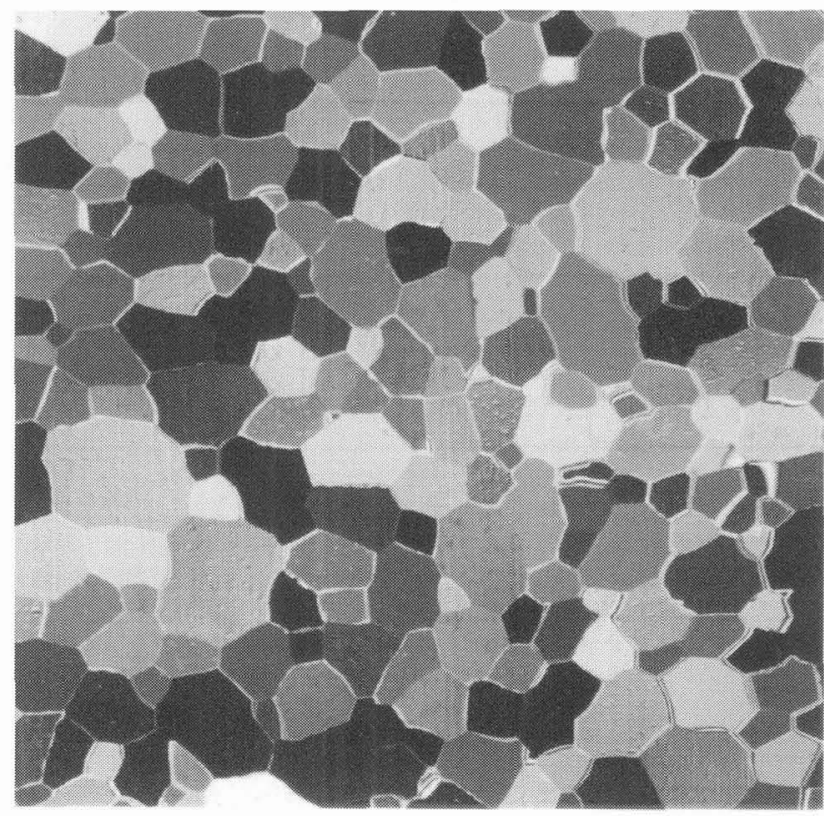

Figure 4. Thin section photograph of artificial ice after grain growth; crystal size is about $5 \mathrm{~mm}$ in diameter. This photograph was taken between crossed polaroids.

\subsection{Rotation recrystallization}

Depending on temperature and strain rate, the average grain size does not increase below a critical depth close to $450 \mathrm{~m}$. at Byrd Station ( mean annual surface temperature : $-28^{\circ} \mathrm{C}$ ) and more than $2500 \mathrm{~m}$. at Vostok Station $\left(-56^{\circ} \mathrm{C}\right.$.). Polygonization and nucleation of new grains are observed. Grain boundaries migrate slowly following the same velocity regime as for grain growth. The grain boundary migration rate corresponding to this low-velocity regime is always lower than $10^{-14} \mathrm{~m}^{2} \cdot \mathrm{s}^{-1}$ (figure 5).

Rotation recrystallization requires the formation of sub-boundaries and leads to heterogeneous deformation within grains. Kink bands are a familiar feature in the deformation of ice [22]. Their formation is a mechanism by which bending moments can be relieved. Basal dislocations are grouped together in walls more or less perpendicular to slip planes. Obviously, bending moments result from the high plastic anisotropy of ice crystals, which imposes a non-uniform state of stress within the polycrystal. Rotation recrystallization in polar ice is generally characterized by the maintenance of an equiaxed grain structure. However, elongated grains are observed in the Vostok ice core indicating a convergent flow [5]. This recrystallization mechanism (subgrain formation, nucleation of grains and low velocity grain boundary migration) concerns a large part of ice in polar ice sheets. Depending on strain rates and the ability of moving grain boundaries to accommodate dislocation glide, the value of the stress exponent can also be lower than 3 [7].

\subsection{Migration recrystallization}

Near the bottom of ice sheets, high temperatures allow the nucleation of new grains and the rapid migration of grain boundaries. In situ data indicate that this recrystallization mechanism occurs only above a critical temperature close to $-10^{\circ} \mathrm{C}$. The grain boundary migration rate ranges from $10^{-12} \mathrm{~m}^{2} \cdot \mathrm{s}^{-1}$ to $10^{-8} \mathrm{~m}^{2} \cdot \mathrm{s}^{-1}$ near the melting point [16] (figure 5). This recrystallization mechanism is known to occur in polycrystalline ice after a critical strain which can be less than 1\% [23]. Migration recrystallization can be a discontinuous 
process. As soon as recrystallization starts, a wave of recrystallization and subsequent strain hardening passes through the sample producing a wave of accelerating creep [23]. The main difference with respect to metals and ceramics lies in the small critical strain. From Duval et al. [16], the high strain energy necessary to initiate recrystallization is reached in crystals badly oriented for basal glide, which are the more loaded [2].

The fast grain boundary migration tends to produce an interlocking texture (figure 6). But, for a constant applied stress, the continuous sequence of nucleation and growth can result in a constant mean grain size. The possibility of using crystal size as a piezometer was discussed by Derby [24] for a range of materials. It was shown that migration recrystallization is characterized by a universal relationship between mean grain size and stress normalized by shear modulus. This relationship was also verified for ice by Jacka and Li Jun [25]. This reflects the balance between nucleation and the grain boundary migration rate. On the other hand, this relation implies that grain size adjusts rapidly to a change of stress. The small accumulated strain $(<1 \%)$ necessary to initiate recrystallization and the high velocity of grain boundary migration explains this relation between grain size and stress.

\section{THE ROLE OF DYNAMIC RECRYSTALLIZATION IN THE DEVELOPMENT OF LATTICE PREFERRED ORIENTATIONS}

An assessment of the effect of dynamic recrystallization on the lattice preferred orientation in polar ice depends on an accurate identification of recrystallization mechanisms and deformation modes. The description of the deformation of the polycrystal can provide some elements to analyze fabrics. The selfconsistent theory indicates that basal slip contributes to more than $90 \%$ of the deformation. Grains which have a low resolved shear stress on basal planes have to use other slip systems which are much harder to activate. For ice, the resistance for prismatic slip is found to be 20 times higher than for basal slip. As shown in figure 2, grains poorly oriented for basal glide are the more stressed. But, at low stresses, grain

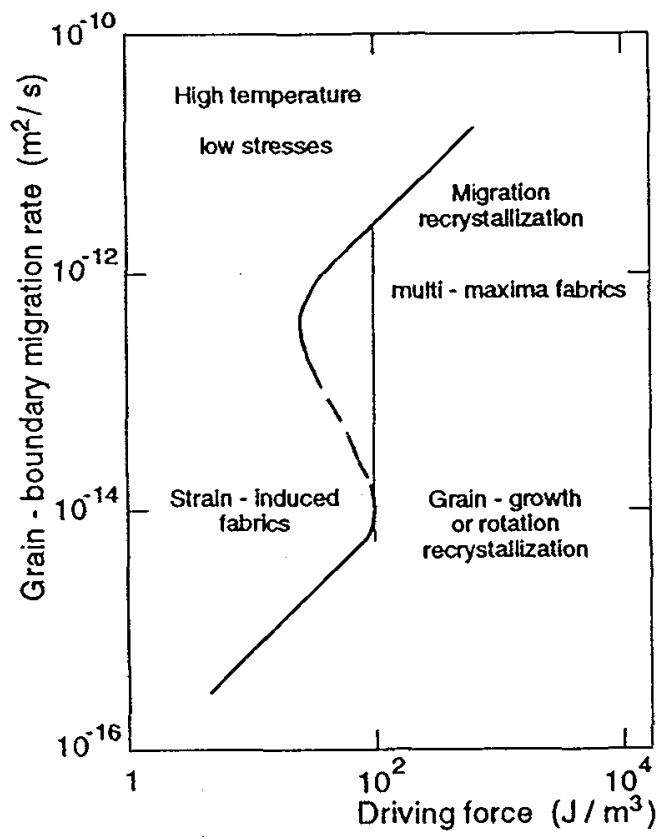

Figure 5. The velocity of grain boundary migration as a function of driving force in the temperature range -10 to $-15^{\circ} \mathrm{C}$.

boundary migration associated with grain growth and rotation recrystallization seems to be an efficient accommodation process for dislocation glide and to be at the origin of the low value of the stress exponent. Consequently, we expect a more uniform state of stress within the polycrystal. However, soft grains oriented for basal slip should be always the least stressed even if prismatic slip is less necessary for the deformation. 
To discuss the role of dynamic recrystallization in the development of fabrics, the effect of lattice rotation by intracrystalline slip must be analyzed. The first simulations were done by Castelnau and Duval [26] using the stress equilibrium assumption (lower bound). In compression and tension, $\mathrm{C}$-axes progressively take an orientation which impedes basal slip and makes ice harder (figure 7). The elastic strain energy of the stored dislocations is the driving force for the nucleation of grains. Nucleation occurs for regions where there is curvature of basal planes by the formation of sub-boundaries perpendicular to slip planes. The origin of kinks was discussed by Wilson et al. [27]. Several mechanisms, which depend on the orientation of basal planes with respect to the shortening direction, were analyzed. The strong plastic anisotropy of ice crystals is responsible for the formation of tilt sub-boundaries normal to the slip direction. New grains are nucleated within kink bands or by grain boundary bulging. The nucleation of grains by lattice rotation and subgrain growth will be more important in grains unsuitably oriented for basal glide, i.e. the more loaded. A similar result is expected for grain boundary bulging.

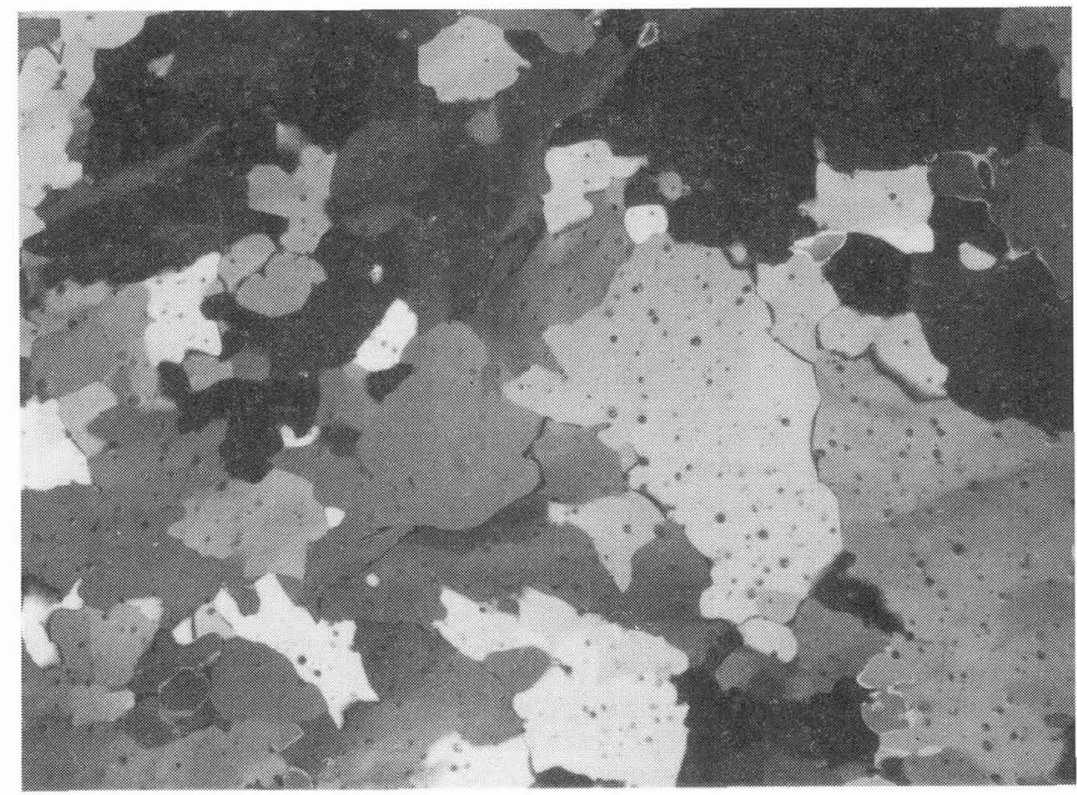

Figure 6. Thin section photograph of Antarctic ice from Terre Adélie (depth: 70m); average crystal size is about $10 \mathrm{~mm}$ in diameter. This photograph was taken between crossed polaroids.

The role of dynamic recrystallization in the development of fabrics will also depend on the rate of grain boundary migration. In the last $300 \mathrm{~m}$ of the Byrd ice core, extensive migration recrystallization occurs with a shear strain rate of about $10^{-9} \mathrm{~s}^{-1}$ at $-10^{\circ} \mathrm{C}$. The grain boundary migration rate is about $10^{-11} \mathrm{~m}^{2} \cdot \mathrm{s}^{-1}$. A new grain microstructure is therefore expected for a strain smaller than $1 \%$. This is roughly in accordance with laboratory measurements for which a wave of recrystallization is obtained for a strain of about $5 \%$ [23]. In the high grain boundary migration regime, lattice rotation by intracrystalline slip is therefore ineffective to induce lattice preferred orientation and fabrics are stress-controlled. Since new recrystallized grains are suitably oriented for basal glide and favored for growth ("hard" grains store more strain energy), migration recrystallization should produce grains well oriented for basal slip. This has already been confirmed for temperate ice [28].

When only grain growth occurs, the migration rate of grain boundaries is less than $10^{-14} \mathrm{~m}^{2} \cdot \mathrm{s}^{-1}$ (figure 5). The strain energy of dislocations is low compared with grain boundary energy. So, the nucleation of grains cannot occur. Fabrics associated with this recrystallization mechanism result only from lattice rotation by dislocation glide.

During rotation recrystallization, polygonization occurs; but, grain boundary migration is still too slow to significantly influence the fabric development. However, the nucleation and growth of grains well oriented for basal slip should slow down the kinetics of fabric development by lattice rotation. A special case concerns the fabrics obtained in simple shear. Using the self-consistent theory, a fabric with $C$-axes close to 
the direction of the maximal compression is obtained [26]. A similar result was obtained by Wenk et al. [30] on peridotite. A metastable orientation with basal planes oriented in the macroscopic shear plane is found (easy slip). This orientation can be stabilized by recrystallization as assumed by Bouchez and Duval [29].
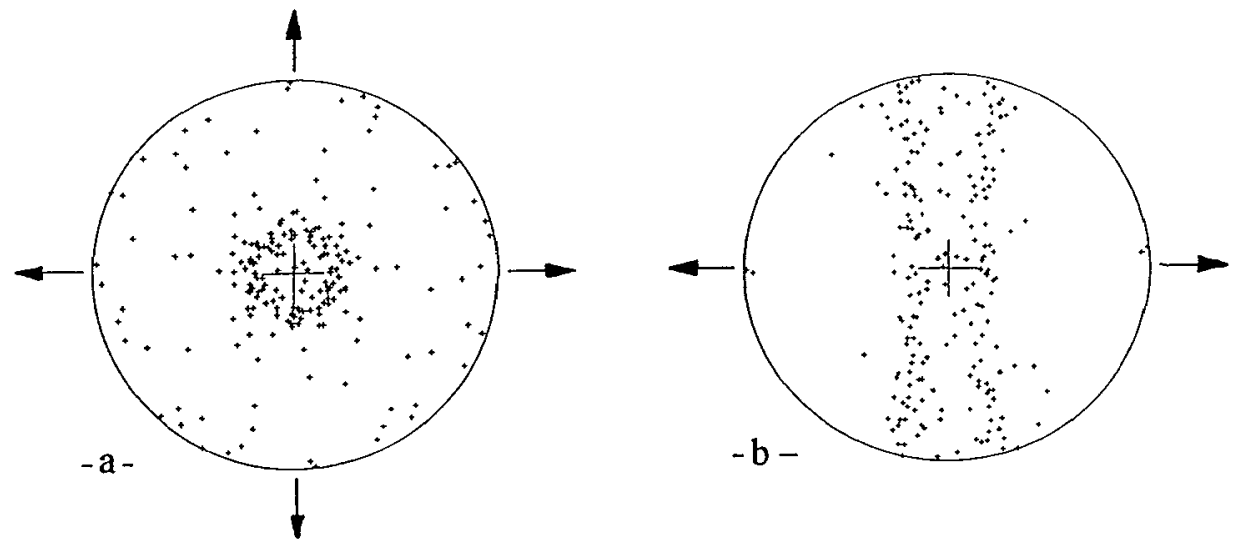

Figure 7. Simulated C-axes fabric diagrams for an initially isotropic ice sample deformed with the uniform stress assumption: a/ to $25 \%$ equivalent strain under uniaxial compression $\mathrm{b} /$ to $30 \%$ equivalent strain under uniaxial tension.

\section{CONCLUSIONS}

For conditions prevailing in polar ice sheets, dislocation glide on basal planes is the dominant deformation process. The self-consistent theory used in this work indicates that overall inelastic deformation of polycrystalline ice is possible with hard prismatic slip. The strong plastic anisotropy of ice crystals is responsible for the development of a non-uniform internal stress field within the polycrystal during creep. As creep relaxes the resolved shear stress on the basal plane, load is transferred to the harder systems.

In polar ice sheets, the grain texture modification is achieved via three successive recrystallization mechanisms: grain growth, rotation recrystallization and migration recrystallization.

The lattice preferred orientation of recrystallized ice is determined by the relative rate of deformation and grain boundary migration. During grain growth and rotation recrystallization, lattice rotation by intracrystalline slip is the dominant mechanism and fabrics reflect the strain history. During migration recrystallization, the nucleation of grains and grain boundary migration need a small strain to replace old grains by new grains and fabrics reflect the stress state. The next step in this study will be to include recrystallization in the self-consistent theory to obtain a better assessment of the fabric evolution during creep.

\section{Acknowledgments}

This work was supported by PNEDC (Programme National d'Etudes de la Dynamique du Climat) CNRS, France and by the CEC (Commission of European Communities) Environment Programme. We are very grateful to G. Canova, R. Lebensohn and C. Tomé for fruitful discussions and for allowing us to use their self- consistent model.

\section{References}

[1] Pimienta P. and Duval P., J. Phys. France C1 (1987) 243-248

[2] Lliboutry L.and Duval P., Ann. Geophysicae 3 (2) (1985) 207-224

[3] Gow A.J. and Williamson T., CRREL Report 7635 (1976) 1-25

[4] Herron M.M. and Langway C.C., "Greenland Ice Core: Geophysics, Geochemistry and the Environment", Geophysical Monograph 33 (1985) 77-84

[5] Lipenkov V.Ya., Barkov N.I. Duval P. and Pimienta P., J. of Glaciology 35 (1989) 392-398

[6] Azuma R.B. and Higashi A., Ann. Glaciology 6 (1985) 130-134 
[7] Alley R.B., J. of Glaciology 38 (1992) 245-256

[8] Gundestrup N.S. and Hansen B.L., J. of Glaciology 30 (1984) 282-288

[9] Pimienta P., Duval P.and Lipenkov V.Ya., IAHS Publ. 170 (1987) 57-66

[10] Budd W.F. and Jacka T.H., Cold Reg. Sc. Tech. 16 (1989) 107-144

[11] Paterson W.S.B., Cold Reg. Sc. Tech. 20 (1991) 75-98

[12] Pimienta P. and Duval P., Ann. Glaciology 12 (1989) 206

[13] Guillopé M. and Poirier J.P., J.Geophy. Res. 84 B10 (1979) 5557-5567

[14] Thorsteinsson Th. and Kipfstuhl S., Verbal communication

[15] Lebensohn R.A. and Tomé C.N., Acta Met. 41 (1993) 2611-2624

[16] Duval P., Ashby M.F. and Anderman I., J. Phys. Chemistry 87 (1983) 4066-4074

[17] Hutchinson J.W., Metal. Transactions 8A (1977) 1465-1469

[18] Hondoh T., Iwamatsu H. and Mae S., Phil. Mag. 62 (1990) 89-102

[19] Shearwood C. and Whitworth R.W., Phil. Mag. 64 (1991) 289-302

[20] Petit J.R. Duval P. and Lorius C., Nature 326 (1987) 62-64

[21] Legrand M., J. Phys. France C1 (1987) 77-86

[22] Wilson C.J.L., "Mineral and rock deformation: laboratory studies" Geophysical Monograph 36 (1986) 213-232

[23] Steinemann S., I.A.S.H. Publ. 47 (1958) 184-198

[24] Derby B., Scripta Met. 27 (1992) 1581-1586

[25] Jacka T.H. and Li Jun, Ann.Glaciology (in press)

[26] Castelnau O. and Duval P., Ann. Glaciology (in press)

[27] Wilson C.J.L., Burg J.P. and Mitchell J.C., Tectonophysics 127 (1986) 27-48

[28] Duval P., J. of Glaciology 27 (1981) 129-140

[29] Bouchez J.L. and Duval P., Text. and Microstructures 5 (1982) 171-190

[30] Wenk H.R.,Bennett K., Canova G.R.and Molinari A., J. Geoph. Res. 96 (1991) 8337-8349 